This article was downloaded by: [UPEC - Prehospital Emergency Care]

On: 10 November 2008

Access details: Access Details: [subscription number 768277147]

Publisher Informa Healthcare

Informa Ltd Registered in England and Wales Registered Number: 1072954 Registered office: Mortimer House, 37-41 Mortimer Street, London W1T 3JH, UK

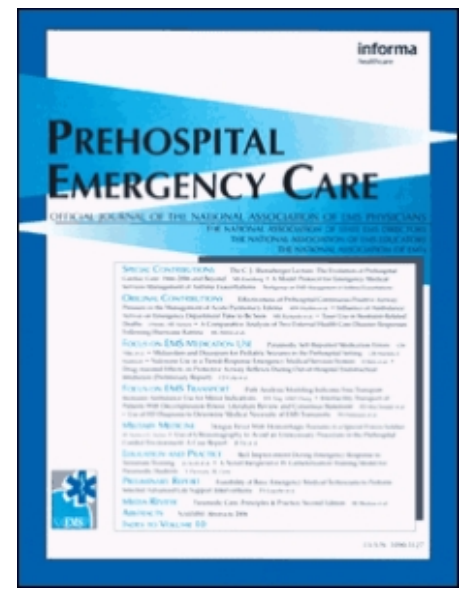

Prehospital Emergency Care

Publication details, including instructions for authors and subscription information:

http://www.informaworld.com/smpp/title content=t713698281

\title{
Helicopter Scene Response: Regional Variation in Compliance with Air Medical
} Triage Guidelines

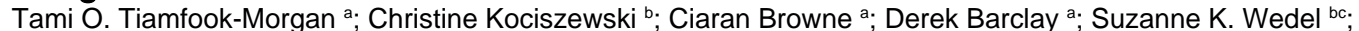
Stephen H. Thomas ab

a Harvard Affiliated Emergency Medicine Residency Program and Massachusetts General Hospital, Boston, Massachusetts ${ }^{\mathrm{b}}$ Boston MedFlight Critical Care Transport Service, Bedford, Massachusetts ${ }^{\mathrm{c}}$ Department of Surgery, Boston University School of Medicine, Boston, Massachusetts

Online Publication Date: 01 September 2008

To cite this Article Tiamfook-Morgan, Tami O., Kociszewski, Christine, Browne, Ciaran, Barclay, Derek, Wedel, Suzanne K. and Thomas, Stephen H.(2008)'Helicopter Scene Response: Regional Variation in Compliance with Air Medical Triage

Guidelines',Prehospital Emergency Care,12:4,443 - 450

To link to this Article: DOI: $10.1080 / 10903120802290794$

URL: http://dx.doi.org/10.1080/10903120802290794

\section{PLEASE SCROLL DOWN FOR ARTICLE}

\footnotetext{
Full terms and conditions of use: http://www.informaworld.com/terms-and-conditions-of-access.pdf

This article may be used for research, teaching and private study purposes. Any substantial or systematic reproduction, re-distribution, re-selling, loan or sub-licensing, systematic supply or distribution in any form to anyone is expressly forbidden.

The publisher does not give any warranty express or implied or make any representation that the contents will be complete or accurate or up to date. The accuracy of any instructions, formulae and drug doses should be independently verified with primary sources. The publisher shall not be liable for any loss, actions, claims, proceedings, demand or costs or damages whatsoever or howsoever caused arising directly or indirectly in connection with or arising out of the use of this material.
} 


\title{
Helicopter SCene Response:
}

\section{Regional Variation in Compliance with Air Medical Triage Guidelines}

\author{
Tami O. Tiamfook-Morgan, MD, Christine Kociszewski, EMT-P, MPH, Ciaran Browne, MBBS, \\ Derek Barclay, MD, Suzanne K. Wedel, MD, Stephen H. Thomas, MD, MPH
}

\section{ABSTRACT}

Background. Our state has consensus guides for helicopter emergency medical services (HEMS) scene dispatch, based on physiologic, anatomic, and special criteria (e.g., ejection from a vehicle, age $<10$ or $>55$ years). There has been much attention paid to improving HEMS triage criteria, but less focus on whether current HEMS uses meet existing criteria. Objectives. To assess a HEMS program's compliance with regional air medical dispatch guidelines and to identify factors associated with noncompliant flights. Methods. Using chart review and discussion with referring agencies, we conducted a consecutive case review of a HEMS program's initial 100 flights in one year (2005), collecting data pertinent to triage, prehospital times, and hospital course. Analysis $(p=0.05)$ of the outcome "met triage criteria" (MTC) used Kruskal-Wallis and Fisher's exact tests. Logistic regression, reporting odds ratios (ORs) with 95\% confidence intervals (CIs), was used to adjust for covariates while assessing predictors of the dichotomous outcome MTC. The predictors assessed included demographics, advanced life support (ALS) scene presence, and whether transports occurred during rush hours (0700-1000 and 1600-1900). Results. The 100 patients (98 blunt trauma; $73 \%$ male) from four Massachusetts emergency medical services (EMS) regions $(n=94)$ and New Hampshire $(n=6)$ were classified as MTC in $73 \%$ of cases. Physiologic criteria were met in $19 \%$ of cases (they were the sole criterion met in one case), anatomic criteria in $49 \%$ (sole criterion $n=24$ ), and special criteria in $67 \%$ (sole criterion $n=15$ ). There was no association between MTC status and age $(p=0.98)$, gen$\operatorname{der}(\mathrm{p}=0.39)$, rush-hour transport $(\mathrm{p}=0.81)$, or ALS-trained ground EMS presence on scene $(\mathrm{p}=0.98)$. Analysis adjusting for transport distance and injury mechanism identified an association between EMS region and MTC transport status $(\mathrm{p}=$ 0.006); regions' likelihoods of MTC proportions ranged from

Received February 25, 2008, from the Harvard Affiliated Emergency Medicine Residency Program and Massachusetts General Hospital (TOTM, CB, DB, SHT), Boston, Massachusetts; Boston MedFlight Critical Care Transport Service (CK, SKW, SHT), Bedford, Massachusetts; and the Department of Surgery, Boston University School of Medicine (SKW), Boston, Massachusetts. Revision received May 13, 2008; Accepted for publication May 22, 2008.

Presented in part at the 4th Mediterranean Emergency Medicine Congress, Sorrento, Italy, September 2007, and at the American Academy of Emergency Medicine 14th Annual Scientific Assembly, Amelia Island, Florida, February 2008.

Address correspondence and reprint requests to: Stephen H. Thomas, MD, MPH, Massachusetts General Hospital Department of Emergency Services, Zero Emerson Place Suite 3B, Boston, MA 02114-2241. e-mail: thomas.stephen@mgh.harvard.edu

doi: $10.1080 / 10903120802290794$
$50 \%$ to $94 \%$. Conclusion. Despite promulgation of consensus guidelines, nearly a fourth of HEMS transports were nonMTC. Wide interregional variation in the likelihood of MTC HEMS use provides a focus for further research/education. Regional systems should strive not only for the refinement of, but also the compliance with, HEMS triage guidelines. Key words: helicopter EMS; prehospital; trauma triage; utilization review

PREHOSPITAL EMERGENCY CARE 2008;12:443-450

\section{INTRODUCTION}

The preponderance of available evidence suggests a potential outcomes benefit for scene helicopter emergency medical services (HEMS) transport of injured patients. ${ }^{1-3}$ The importance of air medical transport as a component of U.S. trauma care has been widely acknowledged. ${ }^{4,5}$ However, there are persistent and significant challenges in the identification, at the time of prehospital vehicle triage, of patients who will likely benefit from air medical dispatch. ${ }^{6-9}$

In fact, triage refinement may be the most pressing research need in HEMS. Both HEMS supporters and detractors agree that, just as trauma triage in general remains an imperfect science, there is room for improvement in air medical triage. ${ }^{9,10}$ Thus, the major thrust of ongoing research in the air medical triage arena is aimed toward identifying HEMS activation criteria that optimize helicopter utilization. The prime importance of elucidating high-performing triage criteria is acknowledged, but the current study was undertaken to address a different, more "downstream," issue: regional compliance with triage guidelines that are already in place.

In the years before the study was conducted, a consensus approach was taken in our state, to generate HEMS triage guidelines. The resulting guidelines for air medical use (Table 1) are imperfect, but they have the advantage of representing a single, objective set of HEMS use criteria, promulgated by the Commonwealth of Massachusetts Office of EMS, and applicable statewide. Thus, even while the past few years' emerging trauma triage data. ${ }^{11,12}$ have resulted in ongoing work to update the guidelines, there are important lessons to be learned from assessing our region's performance in complying with the existing criteria. Since even the best triage guidelines are unhelpful if they are not followed, it is hoped that 
TABLE 1. Massachusetts Statewide Trauma and Triage Criteria (for Helicopter Scene Dispatch)

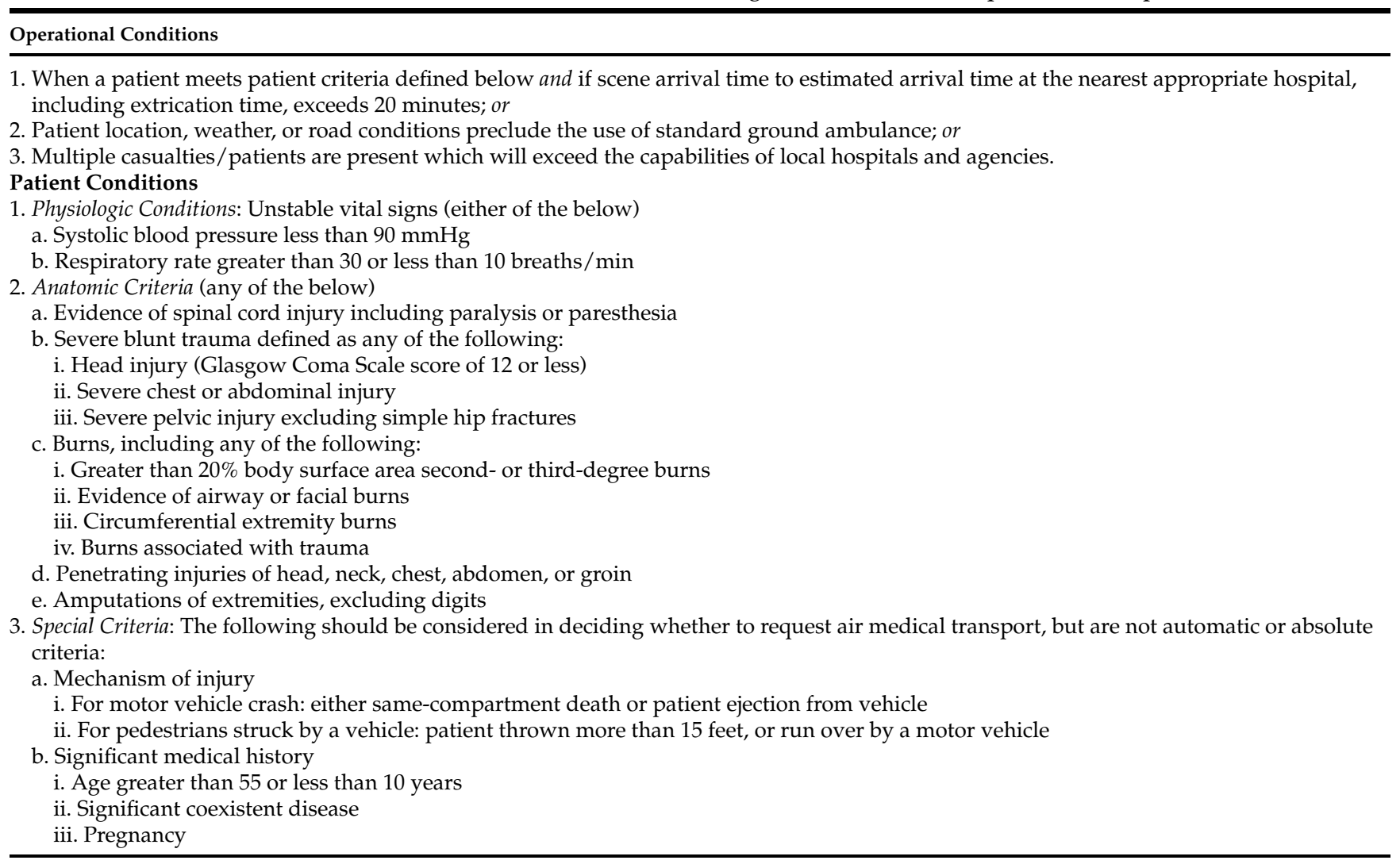

the current study can assist in the overall process of optimizing use of the helicopter resource.

This study's specific goals were thus to: 1) assess one HEMS service's scene responses to determine the rate of compliance with our state's HEMS dispatch guidelines and 2) determine whether there were identifiable (and possibly remediable) factors associated with outof-guideline helicopter use.

\section{MethODS}

\section{Setting}

The study was conducted at Boston MedFlight (BMF), which at the time of the study operated two rotor-wing aircraft. A nurse and paramedic crew, operating under direct and indirect medical control, responds to approximately 500 trauma scenes annually. BMF scene response requests are initiated by basic life support (BLS) or advanced life support (ALS) providers, operating under the statewide treatment and triage guidelines (see Table 1). BMF scene responses are nearly exclusively confined to the Commonwealth of Massachusetts, although there are occasional missions to neighboring states. The BMF service area comprises four emergency medical services (EMS) "regions" (in Massachusetts) from which air transport occurs. Patients are transported to one of six urban academic adult and pediatric trauma centers in Boston.

\section{Study Design}

This institutional review board-approved study was retrospective, in that accrual of subjects for the study occurred after transport was completed. Study personnel adjudicated whether HEMS scene transports met statewide criteria by review of transport and hospital records, clarifying triage decision making by direct communications with the EMS personnel who had requested air medical transport.

\section{Variables}

Study variables included location from which air transport occurred, prehospital times, trauma mechanism, and patient characteristics. The study also collected data on patient treatment courses, including HEMS interventions (e.g., intubation, analgesia provision), trauma center workup (e.g., operative intervention), and patient outcome.

The study's dependent variable of main interest was whether a given HEMS scene response met the statewide air medical trauma triage criteria as outlined in Table 1. Those transports that met triage criteria were classified as MTC (i.e., "met triage criteria") transports; other missions were classified as non-MTC. At least two study personnel assessed each case (there were no instances in which assignation of MTC status was in question, so no kappa was assessed given $100 \%$ agreement). 


\section{Analysis}

Descriptive analysis was performed to assess variables such as patient demographic information and the frequency of MTC transports. For nonnormally distributed continuous data, central tendency was assessed by calculation of median with interquartile range (IQR).

Univariate analysis focused on the dichotomous outcome MTC, employing Kruskal-Wallis nonparametric testing (for noncategorical data) and Fisher's exact test (for categorical variables). Multivariate analysis was performed with logistic regression, with results reported as odds ratio (OR) with $95 \%$ confidence interval (CI); the likelihood ratio test (LRT) was used to assess significance of covariates in nested regression models.

All analysis was performed with STATA 10/MP (StataCorp, College Station, TX). For all tests, significance was set at the $\mathrm{p}<0.05$ level.

\section{ReSULTS}

The 100 patients' trauma scene requests came from 76 different agencies in the BMF service area. Patient characteristics, including selected data on patient interventions and follow-up, are shown in Tables 2 and 5.

Information on patient care interventions is provided for descriptive purposes. Pre-HEMS providers intubated nine patients, and administered analgesia in eight cases. The HEMS crew intubated 25 patients. Flight crews also administered opioid analgesia in 75 cases (72 fentanyl, three morphine). (For the 37 cases in which a ten-point numeric pain score was documented, the median was 9 with IQR 8-10.)

Of 100 patients, 73 met the HEMS triage guidelines. Pertinent results are depicted in Table 3.

Univariate analysis failed to identify an association between MTC status and demographics (Table 4), including in the adult versus pediatric age classification, for those patients between 10 and 55 years old $(\mathrm{p}=$ $0.726)$. There was also no gender-related difference in the likelihood of patients' MTC status $(p=0.801)$.

Table 4 also shows lack of univariate association between MTC status and logistics related to referring region, prehospital times, and transport distance.

Multivariate analysis assessed for associations between independent variables and the dependent dichotomous variable MTC. Covariates identified as significant in logistic regression included age (OR 1.07, 95\% CI 1.03-1.11, $\mathrm{p}=0.001$ ) and transport distance (OR $1.05,95 \%$ CI 1.01-1.10, $\mathrm{p}=0.028$ ). A model including these variables and mechanism of injury $(p=0.016$ by LRT) revealed a significant association between referring region and likelihood of MTC status ( $p=$ 0.006 by LRT). Although low study numbers reduced point estimates' robustness, Wald p-values indicated that, as compared with the MTC likelihood (74\%) of
TABLE 2. Patient Characteristics: 100 Study Patients

\begin{tabular}{|c|c|}
\hline Variable & Number of Patients* \\
\hline \multicolumn{2}{|l|}{ Age } \\
\hline Median, range (IQR) & $\begin{array}{l}31,3-84 \text { years } \\
(20-50) \text { years }\end{array}$ \\
\hline \multicolumn{2}{|l|}{ Gender } \\
\hline Male & $73 \%$ \\
\hline Female & $27 \%$ \\
\hline \multicolumn{2}{|l|}{ Trauma mechanism } \\
\hline Penetrating & 2 \\
\hline Fall $\quad 0$ & 13 \\
\hline Pedestrian struck & 11 \\
\hline Burns & 2 \\
\hline Crush & 7 \\
\hline Motor vehicle collision & 51 \\
\hline Motorcycle crash & 8 \\
\hline $\begin{array}{l}\text { Other (various: blunt } n=5 \text {; } \\
\text { electrical injury } n=1 \text { ) }\end{array}$ & 6 \\
\hline \multicolumn{2}{|l|}{ Referring region } \\
\hline Massachusetts Region A & 12 \\
\hline Massachusetts Region B & 16 \\
\hline Massachusetts Region C & 23 \\
\hline Massachusetts Region D & 43 \\
\hline New Hampshire & 6 \\
\hline \multicolumn{2}{|l|}{ Scene ground EMS level } \\
\hline BLS & 14 \\
\hline ALS & 86 \\
\hline \multicolumn{2}{|l|}{ Transport time of day } \\
\hline Evening/nighttime (2000-0600) & 18 \\
\hline $\begin{array}{l}\text { Rush hour (0700-1000 or } \\
1600-1900)\end{array}$ & 30 \\
\hline \multicolumn{2}{|l|}{ Transport distance } \\
\hline Median, range (IQR) & $\begin{array}{l}23,6-88 \text { miles } \\
(16-38) \text { miles }\end{array}$ \\
\hline \multicolumn{2}{|l|}{$\begin{array}{l}\text { Time (median, IQR) from initial } \\
9-1-1 \text { call to: }\end{array}$} \\
\hline HEMS crew arrival at patient & $34(27-40) \mathrm{min}$ \\
\hline Patient arrival at trauma center & $54(48-64) \mathrm{min}$ \\
\hline \multicolumn{2}{|l|}{ Hospital workup } \\
\hline $\begin{array}{l}\text { At least one computed } \\
\text { tomography test }\end{array}$ & 84 \\
\hline Operative intervention & 40 \\
\hline Intensive care unit admission & 33 \\
\hline \multicolumn{2}{|l|}{ Disposition } \\
\hline Died & 13 \\
\hline Home & 66 \\
\hline Rehabilitation & 21 \\
\hline
\end{tabular}

the region (Massachusetts Region D) with the most transports, MTC likelihoods were significantly lower for the New Hampshire patients $(50 \%, \mathrm{p}=0.016)$, and higher for transports out of Massachusetts Region B (94\%, $\mathrm{p}=0.037$ ).

Although the study aimed to assess compliance with, rather than appropriateness of, HEMS triage criteria, some summary data on the non-MTC patients are presented. None were intubated, either before HEMS arrival or during air medical transport. Most (19/27, 70\%) were involved in motor vehicle collisions. There was one patient with each of the following diagnoses: electrical injury, distal digital amputation, and motorcycle crash. Of five non-MTC patients with "fall" mechanism, 
TABLE 3. Helicopter Triage Criteria Met by Study Patients

\begin{tabular}{lr}
\hline Variable & $\begin{array}{c}\text { Number of } \\
\text { Patients }\end{array}$ \\
\hline Physiologic criteria* & 14 \\
Systolic blood pressure $<90 \mathrm{mmHg}$ & 9 \\
Respiratory rate $<10$ or $>30$ breaths $/ \mathrm{min}$ & 18 \\
At least one physiologic criterion met & 1 \\
Physiologic criteria were the only triage criteria met & \\
Anatomic criteria* & 3 \\
Evidence of spinal cord injury & 28 \\
Severe head injury (Glasgow Coma Scale score $\leq 12)$ & 45 \\
Severe abdominal, chest, or pelvic injury & 2 \\
Burns & 2 \\
Penetrating injury & 2 \\
Extremity amputation & 53 \\
At least one anatomic criterion met & 25 \\
Anatomic criteria were the only triage criteria met & \\
Special criteria* & 11 \\
Vehicle ejection or same-compartment death & 11 \\
Pedestrian thrown $>15$ feet or run over by vehicle & 20 \\
Age $<10$ years $(n=3)$ or $>55$ years $(n=17)$ & 5 \\
Multiple special criteria met & 38 \\
At least one special criterion met & 18 \\
Special criteria were the only triage criteria met & 27 \\
Patients meeting no triage criteria & \\
\hline
\end{tabular}

*Many patients met more than one constituent criterion within the physiologic, anatomic, and special categories.

one was a snowboarder airlifted off of a resort mountain after sustaining a hand crush injury, one was kicked in the face by a horse after falling from her saddle, and three sustained falls from 12-, 20-, and 40-foot heights. Although two of these patients underwent nonemergent orthopedic operative intervention, none were seriously injured.

\section{Discussion}

Currently available guidelines for HEMS dispatch are far from ideal. In fact, it can be argued that, as an agenda item for further trauma-related air medical research, improving HEMS triage constitutes the highest priority. In the words of a National Highway Traffic Safety Administration (NHTSA) report:

Better utilization of air medical services can produce reductions in mortality and morbidity of crashes. Such benefits can be achieved with faster response and transport times, higher quality care at the scene and in transport, and at the highest-level trauma center. The goal is to facilitate air medical care when needed, and avoid overutilization when not needed. ${ }^{13}$

The NHTSA authors, confirming that the current triage system needs improvement, emphasize a need to "develop information systems and protocols that help to distinguish those who are likely to have serious injuries from those who are unlikely to have serious injuries." ${ }^{13}$ The need to avoid both over- and under-
TABLE 4. Univariate Analysis: Associations with Failure to Meet Helicopter Triage Criteria

\begin{tabular}{|c|c|c|}
\hline Variable & $\begin{array}{l}\text { Proportion Meeting } \\
\text { Triage Criteria }\end{array}$ & $\mathrm{p}$-Value \\
\hline Age & & 0.726 \\
\hline $10-17$ years & $6 / 10(60 \%)$ & \\
\hline $18-55$ years & $47 / 70(67 \%)$ & \\
\hline Gender & & 0.801 \\
\hline Male & $54 / 73(74 \%)$ & \\
\hline Female & $19 / 27(70 \%)$ & \\
\hline Mechanism & & 0.011 \\
\hline Fall & $8 / 13(62 \%)$ & \\
\hline Motor vehicle collision & $32 / 51(63 \%)$ & \\
\hline Motorcycle crash & $7 / 8(88 \%)$ & \\
\hline Other & $26 / 28(93 \%)$ & \\
\hline Referring region & & 0.113 \\
\hline Massachusetts Region A & $9 / 12(75 \%)$ & \\
\hline Massachusetts Region B & $15 / 16(94 \%)$ & \\
\hline Massachusetts Region C & $14 / 23(61 \%)$ & \\
\hline Massachusetts Region D & $32 / 43(74 \%)$ & \\
\hline New Hampshire & $3 / 6(50 \%)$ & \\
\hline Ground EMS at scene & & 0.161 \\
\hline BLS & $6 / 11(55 \%)$ & \\
\hline ALS & $67 / 89(75 \%)$ & \\
\hline Time of day & & 0.806 \\
\hline $\begin{array}{l}\text { Rush hour (0700-1000; } \\
1600-1900)\end{array}$ & $21 / 30(70 \%)$ & \\
\hline Non-rush hour & $52 / 70(74 \%)$ & \\
\hline $\begin{array}{l}\text { Mettriage criteria: } \\
\text { Median (IQR) }\end{array}$ & $\begin{array}{c}\text { Did not meet triage criteria: } \\
\text { Median (IQR) }\end{array}$ & \\
\hline Transport distance & 23 (17-38) miles 21 (14-35) miles & es 0.273 \\
\hline $\begin{array}{l}\text { Time from initial 9-1-1 call } \\
\text { to HEMS crew arrival at } \\
\text { patient }\end{array}$ & $33(26-40) \mathrm{min} \quad 35(29-46) \mathrm{min}$ & 0.338 \\
\hline $\begin{array}{l}\text { Time from initial 9-1-1 call } \\
\text { to patient arrival at } \\
\text { trauma center }\end{array}$ & $54(47-64) \mathrm{min} \quad 54(49-66) \mathrm{min}$ & 0.787 \\
\hline
\end{tabular}

$\overline{\mathrm{ALS}}=$ advanced life support; $\mathrm{BLS}=$ basic life support; EMS = emergency medical services; HEMS helicopter emergency medical services; IQR = interquartile range.

triage is important to remember, since either error type can result in adverse impacts on both patients and EMS systems. ${ }^{14,15}$

For triage to high-level trauma center care, the American College of Surgeons (ACS) has posited that "an undertriage rate of $5-10 \%$ is considered unavoidable

TABLE 5. Hospital Course and Disposition

\begin{tabular}{ll}
\hline Variable & Number of Patients \\
\hline HEMS interventions & 25 \\
Endotracheal intubation & 75 \\
Fentanyl or morphine analgesia & \\
Hospital workup & 84 \\
At least one computed tomography test & 40 \\
Operative intervention & 33 \\
Intensive care unit admission & \\
Disposition & 13 \\
Died & 66 \\
Home & 21 \\
Rehabilitation & \\
\hline
\end{tabular}

HEMS helicopter emergency medical services. 
and is associated with an overtriage rate of $30-50 \% . " 16$ The overtriage rate most commonly accepted in systems studies approaches $50 \% .{ }^{12,17}$ Such levels of overtriage are easily understood when one begins to review the triage science state-of-the-art. For instance, a large study from New York State finds requirement for major operative intervention in a fourth of registry patients in whom the (low-specificity) criterion "pulse abnormality" was the only triage trigger. ${ }^{18}$ There is no universally accepted rate of appropriate overtriage and undertriage, and in fact there is no "gold standard" for measuring triage accuracy. ${ }^{19}$

Much energy is being devoted to refining trauma triage (and by extension, HEMS dispatch) guidelines, but the task is difficult. Limitation of triage to anatomic and physiologic criteria results in dangerous levels of undertriage-some degree of trauma mechanism and provider judgment needs to be incorporated. ${ }^{18-28} \mathrm{Sim}$ ilarly, restricting HEMS dispatch decision making to a logistics basis is inefficient. ${ }^{29}$ Furthermore, the triage situation is also becoming increasingly complicated by systems issues, which range from ED diversion to subspecialist unavailability. ${ }^{15,20,21}$

Although this study's data include some outcomes information, a relatively small single-center analysis is not well suited to vigorously test triage criteria performance. Thus, while acknowledging the primary import of defining triage guidelines, the current study sought only to determine whether prehospital providers followed existing guidelines. Even ideal triage guidelines-if and when they become available-are not useful if they are not followed. At the time of this study's execution, our EMS region seemed well positioned for an assessment of guidelines compliance, since a widely publicized collaborative effort to update air medical trauma scene dispatch had been executed (and endorsed/promulgated by the state EMS authority) a year before. It is both a study advantage and a limitation (see next section) that our sole intent was to determine whether prehospital HEMS activations were "guideline-compliant."

The study's findings with respect to guideline compliance provided areas for useful focus. Most notably, there was broad variation (50-94\%) between different regions' likelihood of guideline-compliant HEMS missions. Even if the region with the lowest rate of guidelines compliance is discarded from consideration (which is reasonable, given the fact that this 50\% rate was observed in a small population from a neighboring state), the variation among Massachusetts regions provides valuable focus for future educational efforts. Importantly, the study's multivariate analysis confirmed that the association between referral region and guideline compliance remained even after adjustment for patient characteristics and logistics. The suggestion from the results is that, given a similar patient with similar time-distance factors, different regions may have different thresholds for HEMS activation.

Other than regional variation in the appropriateness of HEMS use, there were few easily identifiable predictors of the alignment of air medical dispatches with triage criteria. There were variations in guidelineappropriateness between varying injury mechanisms, but this finding was both predictable and largely unhelpful as a guide for future educational efforts. The predictability of certain mechanisms (e.g., burns, penetrating injury) as being highly correlated with guideline-appropriate triage is based on these mechanisms' being specifically mentioned in the guidelines. Furthermore, there are no obvious educational efforts that will improve guideline compliance for patients with broader mechanisms such as "motor vehicle collision." The injury mechanisms were an important covariate for inclusion in multivariate modeling, to ensure that region-specific variation in guideline compliance was not dependent on casemix. However, the results of this study do not clearly identify remediable injury mechanism-based triage errors.

The authors suspected, incorrectly as it turned out, that HEMS activations occurring during rushhour times would be more likely to be guidelinenoncompliant. In fact, the likelihood of guideline compliance was only very slightly lower for the 30 "rush-hour" patients (70\% vs. $74 \%)$. This difference was not significant in univariate analysis (Table 4), nor was the "rush-hour" term significant when forced into the multivariate model incorporating referring region, injury mechanism, age, and transport distance (rush-hour term $\mathrm{p}=0.478$ by LRT). The multivariate model did suggest that the study had insufficient power to draw final conclusions about association between rush-hour status and criteria-noncompliant HEMS use, since the CIs for the OR (point estimate: $0.64)$ were wide $(0.18-2.22)$.

Related to the issue of rush-hour transports were the other logistics factors assessed in the study. None of these factors were identified as significant predictors of MTC status in univariate analysis. Whereas transport distance was found in multivariate modeling to be a significant predictor of guideline-noncompliant HEMS missions, adjusted analyses failed to identify the other time-distance variables as significant predictors of MTC status. Interestingly, the association between increasing transport distance and MTC status was positive, meaning that guideline-compliant HEMS use was slightly (but statistically significantly) more likely with increasing distance from the receiving trauma centers. Although the results should be considered preliminary, the data from this study's 100 HEMS scene missions are consistent with minimal, if any, HEMS overtriage (in our area) that is attributable solely to logistic considerations. 
Our interpretation of the study's results is that a utilization review process may be able to identify geographic areas within a given HEMS region, for which air medical scene requests are less likely to meet agreedupon guidelines. Based on the results in this study's data, our transport program is collaborating with others in the state to concentrate educational efforts in those areas with lower MTC results. Since educational resources (including crew time and travel abilities) are finite, performance of this study has been beneficial in its effect of allowing better focus of utilization review and associated feedback and education. Currently, Massachusetts HEMS triage guidelines are in a review and update period. Like many areas in the United States, our region has begun to move toward triage guidelines that are consistent with the National Association of EMS Physicians (NAEMSP) guidelines for air medical dispatch.. ${ }^{10}$ When our state's HEMS triage refinement process culminates in updated air medical dispatch criteria, we plan to repeat the current study methodology to assay results of educational interventions (namely, focused feedback and education) implemented as a result of the current study.

It is well known that ongoing assessment of a system's compliance with triage guidelines is an important part of utilization review. As described by others, a number of factors are required for judicious utilization of HEMS resources (e.g., medical oversight, cancellation by on-scene responders, strict utilization review).$^{30}$ Given the facts that rapid transport to trauma centers saves lives. ${ }^{5}$ and that much of the U.S. population can reach Level I centers in a timely fashion only by HEMS, ${ }^{4,31}$ appropriate use of helicopter resources is critical. Both the generation of and the compliance with HEMS triage criteria are worthy areas for trauma care systems' attention.

\section{Limitations}

The current study's most important limitation is its narrow focus. The intent was not to ascertain the discriminatory performance of our state's HEMS triage criteria, but rather to assess prehospital providers' compliance with those criteria. As such, no conclusions should be drawn from the current study's data about the "correctness" of the Massachusetts HEMS triage guidelines.

On a related note, drawing of meaningful conclusions about association between MTC status and injury mechanism is rendered difficult by the triage criteria's specific naming of certain injury mechanisms (e.g., burns, penetrating wounds), which were in turn uniformly predictive of MTC status. Thus, the univariate finding of significant $(p=0.011)$ association between MTC status and injury mechanism (subgrouped a priori into fall, motor vehicle collision, motorcycle collision, and "other") is of importance primarily to demonstrate need to incorporate this variable in multivariate models.

As an additional limitation, while the assigning of MTC status was straightforward (the criteria are fairly simple), the rigorous nature of this study's MTC designation may not have done justice to prehospital providers' need to exercise judgment. In other words, prehospital providers in a given case may be making helicopter activation decisions that-while falling outside the agreed-upon guidelines-represent rational use of HEMS. For instance, one non-MTC patient was a snowboarder evacuated off of a mountain resort after sustaining a fall causing a crush to the hand. This patient was ultimately found to have distal digital injuries that did not require high-level operative management, but it is not clear that prehospital providers on a mountainside should be expected to differentiate operative from nonoperative hand crush injuries. Furthermore, the utility of HEMS in the alpine setting is well described, ${ }^{32}$ but the transport was correctly classified as non-MTC. It is similarly difficult to vigorously criticize HEMS activation for three non-MTC falls, from heights of 12 , 20 , and 40 feet-potentially impressive mechanisms, although the patients' scene examinations and ultimate hospital courses ultimately confirmed "correctness" of the study-assigned non-MTC status. Whereas these debatable points on triage criteria's sensitivity and specificity may have had some influence on the study results, the multivariate assessment adjusting for injury mechanism suggests that such influence was minimal.

An additional point about triage criteria relates to HEMS crew interventions. The Results section provides some air medical crew interventions for informational purposes only. There is no assumption that any of the 25 HEMS intubations was lifesaving. Furthermore, although the provision of opioid analgesia to patients in severe (untreated) pain was doubtless beneficial, the fact that HEMS represented the only means for potent analgesia does not (in our area) constitute grounds for helicopter dispatch.

In a successful effort to obtain a consecutive case series, with conversations with both pre-HEMS providers and receiving trauma centers, the study size was limited to 100 scene transports. As noted in the Results section, this number may have been too small to provide robust point estimates for some independent variables (e.g., rush-hour transport status). However, the study's $n$ was clearly sufficient to identify as statistically significant the major a priori-defined variable of interest: regional variation in MTC likelihood.

This study's focus on scene HEMS requests means the methodology was limited to assessment of prehospital providers,' not physicians,' activation of air transport. We think it is important to point out that while prehospital provider triage is not perfect, neither is physician triage of helicopter transport resources. It should be noted, however, that physician 
HEMS referrals (for interfacility trauma flights) are not consistently sensible from a resource-utilization standpoint. $^{20,21,33}$ The issue of physician triage is related to the current study's focus, in that those critical of EMS triage performance should keep in mind that even physician triage shows considerable room for improvement. In fact, prehospital trauma triage may be just as accurate as that which occurs at the community hospital. ${ }^{34}$ Assessment of over 10,000 injured patients undergoing initial evaluation at 43 non-trauma center community/rural hospitals in Oregon. ${ }^{33}$ found that even after adjusting for patient and hospital-logistic characteristics, there was substantial heterogeneity between different institutions' transfer practices. When it comes to transferring patients (by either ground or air), there seems to be room for improvement regardless of whether transport decisions are made by community hospital physicians or prehospital providers. Just as paramedic judgment remains an important component with demonstrated potential to improve prehospital triage, ${ }^{21}$ "physician discretion" remains an important (and subjective) part of secondary/physician triage. ${ }^{20}$

The information in this study is believed to be potentially useful for other systems, in that it clearly demonstrates the need for attention to compliance with agreed-upon protocols. Our results have shown our region that while we continue to work on refining protocols, similar attention should be focused in our system (and others) on ensuring prehospital providers' compliance with existing guidelines. Although the current study focused on HEMS triage decision making by prehospital personnel, it is also important to focus attention on helicopter activation decisions made by physicians. It seems likely that, just as prehospital providers may benefit from ongoing education about HEMS utilization and appropriateness, similar conversations with physician activators of HEMS transport may be useful.

\section{Conclusions}

While ongoing efforts continue to refine HEMS scene response criteria, it is also important to ensure that prehospital providers consistently comply with triage guidelines in force. The data in this study suggest that there are region-specific variations in HEMS use appropriateness, and that these variations are not explained by either patient- or logistics-related variables. We thus conclude that there is benefit to incorporating regionbased analysis into the utilization review process, because such analysis can assist in focusing ongoing educational efforts. In order to maximize benefits reaped from ongoing improvement in trauma triage science, regional systems should assess whether guidelines that are promulgated are in fact followed. Other systems may benefit from similar self-examination as to whether
HEMS use in their own regions is occurring in compliance with governing guidelines.

The authors are grateful for the assistance from the Boston MedFlight consortium trauma programs: Beth Israel Deaconess Medical Center, Boston Medical Center, Brigham \& Women's Hospital, Children's Hospital, Massachusetts General Hospital, and New England Medical Center.

\section{References}

1. Thomas SH, Cheema F, Wedel SK, et al. Trauma helicopter emergency medical services transport: annotated review of selected outcomes-related literature. Prehosp Emerg Care. 2002;6:359-71.

2. Thomas SH. Helicopter emergency medical services transport outcomes literature: annotated review of articles published 20002003. Prehosp Emerg Care. 2004;8:322-33.

3 . Thomas $\mathrm{S}$. Helicopter emergency medical services transport outcomes literature: annotated review of articles published 20042006. Prehosp Emerg Care. 2007;11:477-88.

4. Branas C, MacKenzie E, Williams J, et al. Access to trauma centers in the United States. JAMA. 2005;293:2626-33.

5. MacKenzie EJ, Rivara FP, Jurkovich GJ, et al. A national evaluation of the effect of trauma-center care on mortality. N Engl J Med. 2006;354:366-78.

6. Shatney C, Homan J, Sherck J, et al. The utility of helicopter transport of trauma patients from the injury scene in an urban trauma system. J Trauma. 2002;53:817-22.

7. Moront M, Gotschall C, Eichelberger M. Helicopter transport of injured children: system effectiveness and triage criteria. J Pediatr Surg. 1996;31:1183-8.

8. Fallon W. Editorial comment following Bledsoe BE, Smith MG. Medical helicopter accidents in the US. J Trauma. 2004;56:1325-9.

9. Bledsoe BE, Wesley AK, Eckstein M, et al. Helicopter scene transport of trauma patients with nonlife-threatening injuries: a metaanalysis. J Trauma. 2006;60:1257-65; discussion 1256-1265.

10. Thomson D, Thomas S. Guidelines for air medical dispatch [NAEMSP position paper]. Prehosp Emerg Care. 2003;7:265-71.

11. Hunt RC, Jurkovich GJ. Field triage: opportunities to save lives. Prehosp Emerg Care. 2006;10:282-3.

12. Salomone JP. Prehospital triage of trauma patients: a trauma surgeon's perspective. Prehosp Emerg Care. 2006;10:311-13.

13. Champion $\mathrm{H}$. New tools to reduce deaths and disabilities by improving emergency care: urgency software, occult injury warnings, and air medical services database. In: Proceedings of the 19th International Technical Conference on Enhanced Safety of Vehicles (NHTSA sponsored), Washington, DC, June 6-9, 2005.

14. O'Connor R E. Trauma triage: concepts in prehospital trauma care. Prehosp Emerg Care. 2006;10:307-10.

15. Mackersie RC. Field triage, and the fragile supply of "optimal resources" for the care of the injured patient. Prehosp Emerg Care. 2006;10:347-50.

16. American College of Surgeons Committee on Trauma. Resources for optimal care of the injured patient. Chicago, IL: American College of Surgeons, 1999.

17. Mango N, Garthe E. Statewide tracking of crash victims' medical system utilization and outcomes. J Trauma. 2007;62:436-60.

18. Henry MC. Trauma triage: New York experience. Prehosp Emerg Care. 2006;10:295-302.

19. Lerner EB. Studies evaluating current field triage: 1966-2005. Prehosp Emerg Care. 2006;10:303-6.

20. O'Connor RE. Specialty coverage at non-tertiary care centers. Prehosp Emerg Care. 2006;10:343-6.

21. Hedges JR, Newgard CD, Mullins R. Emergency Medical Treatment and Active Labor Act and trauma triage. Prehosp Emerg Care. 2006;10:332-9. 
22. Eichelberger M, Gotscholl C, Sacco W, et al. A comparison of the trauma score, the revised trauma score, and the pediatric trauma score. Ann Emerg Med. 1989;18:1053-8.

23. Kaufmann C, Maier R, Rivara F, et al. Evaluation of the pediatric trauma score. JAMA. 1990;263:69-72.

24. Engum S, Mitchell M, Scherer L, et al. Prehospital triage in the injured pediatric patient. J Pediatr Surg. 2000;35:82-7.

25. Cottington E, Young J, Shufflebarger C, et al. The utility of physiologic status, injury site, and injury mechanism in identifying patients with major trauma. J Trauma. 1988;28:305-11.

26. Long W, Bachulis B, Hynes G. Accuracy and relationship of mechanisms of injury, trauma score, and injury severity score in identifying major trauma. Am J Surg. 1986;151:581-4.

27. Newgard CD, Lewis RJ, Jolly B. Use of out-of-hospital variables to predict severity of injury in pediatric patients involved in motor vehicle crashes. Ann Emerg Med. 2002;39:481-91.

28. Gearhart PA, Wuerz R, Localio AR. Cost-effectiveness analysis of helicopter EMS for trauma patients. Ann Emerg Med. 1997;30:500-6.
29. Diaz M, Hendey G, Bivens H. When is the helicopter faster? A comparison of helicopter and ground ambulance transport times. J Trauma. 2005;58:148-53.

30. Hankins DG. Air medical transport of trauma patients. Prehosp Emerg Care. 2006;10:324-7.

31. Svenson J, O'Connor J, Lindsay M. Is air transport faster? A comparison of air versus ground transport times for interfacility transfers in a regional referral system. Air Med J. 2006;24:1702.

32. Kaufmann M, Moser B, Lederer W. Changes in injury patterns and severity in a helicopter air-rescue system over a 6-year period. Wilderness Environ Med. 2006;17(1):8-14.

33. Newgard CD, McConnell KJ, Hedges JR. Variability of trauma transfer practices among non-tertiary care hospital emergency departments. Acad Emerg Med. 2006;13:746-54.

34. Lubin JS, Delbridge TR, Cole JS, et al. EMS and emergency department physician triage: injury severity in trauma patients transported by helicopter. Prehosp Emerg Care. 2005;9:198202. 